\title{
Temas misceláneos sobre COVID-19 en niños
}

\section{Miscellaneous issues on COVID-19 in children}

\author{
Sarahi Hinojosa Maya,* Mario Arturo Flores Valadez,* Jessica Escamilla Villanueva,* \\ Karina Julieta Romo Domínguez,* Elsa Gabriela Saucedo Rodríguez,* Mayra Ivveth Ramos González,* \\ Alejandro Alejandre García, ${ }^{\ddagger}$ Rosangela Del Razo Rodríguez, ${ }^{\S}$ Claudia Garrido Galindo," \\ Pablo Cortés Borrego," Laura Elena Carreto Binaghi," María del Carmen Cano Salas, ** \\ María Cristina Rodríguez-Hernández, ${ }^{\ddagger}$ Concepción Clara Camargo Fajardo, ${ }^{\$ \S}$ Nancy Castillo Linares ${ }^{\llbracket \uparrow}$ \\ * Pediatra. Médico Residente de Neumología Pediátrica. \\ ₹ Neumólogo Pediatra. Jefe de Servicio de Neumología Pediátrica, INER \\ § Neumólogo y Broncoscopista Pediatra. Médico adscrito a Neumología Pediátrica, INER. \\ " Neumólogo Pediatra. Médico adscrito a Neumología Pediátrica, INER. \\ "l Infectólogo Pediatra, Departamento de Investigación en Microbiología, INER. \\ ** Neumólogo Pediatra. Jefe de Postgrado, INER. \\ \# Jefa de Enfermeras de Neumología Pediátrica, INER. \\ $\$ \S$ Doctorante en Ingeniería de Sistemas en Sección de Estudios de Postgrado e Investigación, Instituto Politécnico Nacional. \\ Ћฯ Psicólogo. Adscrito a Neumología Pediátrica, INER.
}

\section{ORGANIZACIÓN Y MATERIAL BÁSICO PARA LAS SALAS DE URGENCIAS}

El objetivo del capítulo es proporcionar recomendaciones sobre tres aspectos: cómo se distribuye el área de urgencias para la atención de pacientes pediátricos con sospecha o confirmación de COVID19, qué material es el adecuado y cuál es la atención a la llegada del paciente. Dichas recomendaciones se encuentran basadas en las guías internacionales como la española ${ }^{1}$ y las recomendaciones de la $\mathrm{OMS},{ }^{2}$ las cuales son aplicadas en nuestro medio con algunas modificaciones.

\section{Atención del paciente en el área de urgencias}

Los pacientes pediátricos que acudan a las instituciones de salud con síntomas de infección respiratoria aguda deben recibir una mascarilla quirúrgica y colocársela de ser posible:

Financiamiento: Ninguno.

Conflicto de intereses: Ninguno.

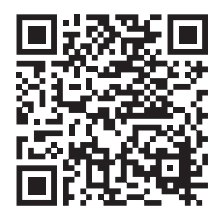

- Si son niños menores de un año que no pueden utilizar mascarilla, deben mantenerse apartados de los demás pacientes.

- Si el niño es mayor de un año y no tolera la mascarilla, debe mantenerse alejado por lo menos a 2 metros del resto de los pacientes.

En la sala de espera, los pacientes con el mismo diagnóstico deben estar agrupados e ingresar con un solo acompañante, también usando una mascarilla quirúrgica en la medida de lo posible. A su llegada, el personal médico o de enfermería debe orientarlos para que se laven las manos, o bien se debe facilitar y ayudar a los niños a utilizar adecuadamente la solución de alcohol/gel y advertir que no debe tener contacto con los ojos ni ser ingerida.

El personal médico puede usar mascarilla quirúrgica si se trabaja a 1 metro del paciente. Las precauciones estándar siempre deben aplicarse en todas

Citar como: Hinojosa MS, Flores VMA, Escamilla VJ, Romo DKJ, Saucedo REG, Ramos GMI et al. Temas misceláneos sobre COVID-19 en niños. Rev Latin Infect Pediatr. 2020; 33 (s1): s75-s95. https://dx.doi. org/10.35366/96673 
las áreas de las instalaciones de atención médica, las cuales incluyen la higiene de las manos y el uso de EPP cuando se encuentre en contacto indirecto y directo con la sangre, los fluidos corporales, las secreciones (incluidas las secreciones respiratorias) y la piel no intacta de los pacientes. Las precauciones estándar incluyen: prevención de pinchazos con agujas o lesiones por objetos punzantes; gestión segura de residuos; limpieza y desinfección de equipos, y limpieza del medio ambiente.

Una vez hospitalizados, los pacientes deben colocarse en habitaciones individuales o agrupados según el diagnóstico etiológico. Si no es posible el diagnóstico etiológico, se agrupará a los pacientes según la sospecha.

Otras medidas para disminuir el riesgo de transmisión son:

- Limitar el movimiento del paciente dentro de la institución únicamente para lo indispensable y asegurarse de que los pacientes usen mascarillas médicas cuando estén fuera de sus habitaciones.

- Evitar contacto, sea a través de la transmisión directa o indirecta con superficies o equipos contaminados (por ejemplo, tubos o interfases de oxígeno contaminados).

- De ser posible, usar equipo desechable (termómetros, estetoscopios, brazaletes de toma de tensión arterial, oxímetros de pulso), pero si tienen que ser compartidos, limpie y desinféctelos entre cada paciente.

En cuanto al personal de salud, se recomienda tener las siguientes consideraciones:

- Debemos asegurarnos de que no toquen sus ojos, nariz y boca con las manos potencialmente contaminadas, ya sea enguantadas o sin guantes.

- Evitar contaminar superficies ambientales que no están relacionadas con el paciente, como son manijas de puertas o interruptores de luz.

- El personal de salud que realiza procedimientos con generadores de aerosoles (succión abierta del tracto respiratorio, intubación, broncoscopia y reanimación cardiopulmonar) debe usar todo el equipo, incluido guantes, protección para ojos y respiradores de partículas N95 con prueba de ajuste o con mayor protección.

- Evite la presencia innecesaria de personas en la habitación.

\section{Áreas recomendadas y su equipamiento}

Recomendamos que el área cuente con cinco áreas:

1. Sala de triaje.

2. Sala de pacientes COVID-19 para la toma de muestras y revisión del paciente.

3. Sala de observación de pacientes con COVID-19.

4. Sala de choque.

5. Sala de cambiado, lavado y desinfección.

1. Sala de triaje: contiene lo necesario para la revisión de pacientes no COVID-19 (es decir, que no cumplan la definición operacional de contacto o sospecha 0 diagnóstico) que acuden a atención médica.

En los hospitales COVID-19, en la entrada el médico interroga sobre los síntomas respiratorios y digestivos del paciente; si cumple con la definición operacional de caso sospechoso o confirmado, pasa a la atención directamente a sala 2 .

En los hospitales no COVID-19, se cuenta con sala de triaje, en la cual se puede interrogar al paciente sobre dichos síntomas.

El personal de salud debe tener la siguiente vestimenta:

- Pijama quirúrgica de tela.

- Cubrebocas quirúrgico y siempre se mantendrá a 1.5 metros de distancia del paciente.

Debe contar con el siguiente material para uso exclusivo de esa sala (el material no debe salir del lugar):

- Estetoscopio.

- Otoscopio.

- Báscula y estadímetro.

- Oxímetro de pulso.

- Termómetro.

- Tarja para lavado de manos.

- Gel antibacterial.

- Cubrebocas quirúrgicos para el paciente y familiar.

- Guantes estériles y no estériles.

- Bolsa roja para desechos.

Se debe evitar la revisión de faringe del paciente para disminuir riesgo de aerosolización.

2. Sala de pacientes COVID-19: contiene lo necesario para la revisión de pacientes con COVID-19 que acuden a atención médica. 
Rev Latin Infect Pediatr 2020; 33 (s1): s75-s95

El personal de salud debe tener la siguiente vestimenta al entrar:

- Pijama quirúrgica de tela.

- Pijama quirúrgica desechable.

- Bata impermeable.

- Zapatos impermeables y cubrezapatos.

- Gafas protectoras cerradas.

- Respirador N95.

- Gorro desechable.

- Doble par de guantes.

Antes de ingresar a la sala, debe colocarse todo el equipo con el procedimiento adecuado para evitar que se contamine su vestimenta u otras superficies.

Debe contar con el siguiente material para uso exclusivo de esa sala (el material no debe salir del lugar):

- Estetoscopio.

- Otoscopio.

- Báscula y estadímetro.

- Oxímetro de pulso.

- Termómetro.

- Gel antibacterial.

- Papel y plumas de uso exclusivo de la sala.

- Tripié para colgado de batas.

- Tarja para lavado de manos.

- Abatelenguas.

- Equipo para toma de muestras orofaríngeas y nasofaríngeas del paciente sospechoso COVID-19.

- Cubrebocas quirúrgicos para el paciente y familiar.

- Guantes estériles y no estériles.

- Bolsa roja para desechos.

3. Sala de observación de pacientes COVID-19: es el lugar donde se da atención primaria al paciente con sospecha o confirmación de COVID-19, los cuales requerirán hospitalización u observación y/o se encuentran en espera de resultados.

El personal de salud debe tener la misma vestimenta al entrar a la sala que la referida a la sala 2. Además, al ingresar a la sala 3 , debe colocarse la bata impermeable que se encuentra asignada a cada paciente, con el procedimiento adecuado para evitar que se contamine su vestimenta u otras superficies.

Debe contar con el siguiente material para uso exclusivo de esa sala (el material no debe salir del lugar):

- Estetoscopio.

- Oxímetro de pulso.
- Termómetro.

- Tarja para lavado de manos.

- Gel antibacterial.

- Papel y plumas de uso exclusivo de la sala, así como carpetas de expediente clínico.

- Tripié para colgado de batas.

- Monitor de TA con mangos de diferentes tamaños.

- Aerocámaras de diferentes tamaños con MDI con esteroides inhalados y broncodilatadores:

- Fluticasona, budesonida o beclometasona, o cualquier otro esteroide.

- Salbutamol o combivent.

- Tomas de oxígeno suplementario con diferentes dispositivos y en diferentes tamaños:

- Puntas nasales pediátricas y adultos.

- Mascarilla facial con y sin reservorio, con y sin válvula unidireccional.

- Mascarillas simples.

- Cascos cefálicos de diferentes tamaños.

- Equipo de aspiración con sondas de diferentes diámetros (8, 10 y 12 FR).

- Material para canalización:

- Catéter intravenoso 24 G y 22 G.

- Torundas con alcohol.

- Material para fijación.

- Soluciones para el paciente:

- Solución fisiológica a $0.9 \%$.

- Solución glucosada a 5\%.

- Solución glucosada a 10\%.

- Solución Ringer Lactato.

- Bombas de infusión.

- Batas para los familiares.

- Cubrebocas quirúrgicos para el paciente y familiar.

- Guantes estériles y no estériles.

- Bolsa roja para desechos.

4. Sala de choque de pacientes COVID-19: es el lugar donde se da atención de urgencia para estabilizar al paciente con sospecha o confirmación de COVID-19.

El personal de salud debe tener la misma vestimenta al entrar a la sala que la referida a la sala 2. Al ingresar a la sala 4 , debe colocarse la bata impermeable que se encuentra asignada a cada paciente, con el procedimiento adecuado para evitar que se contamine su vestimenta u otras superficies.

Debe contar con el mismo material que la sala 3 , agregando además:

- Monitor con desfibrilador, palas estándar adulto y pediátricas, cables, pasta conductora y electrodos. 
- Laringoscopios con hojas rectas y curvas pediátricas.

- Rectas: 0, 1, 2.

- Curvas: 1, 2 y 3 y 4 .

- Cánulas para intubación del paciente pediátrico: - Del 2.5 a 7.5.

- Cánulas orofaríngeas: 50, 60, 70 y 80 mm (0 a 5).

- Mascarillas faciales con manguito de cámara de aire, redondas (lactante) y para niños (triangulares).

- Bolsa-mascarilla reservorio para pacientes pediátri$\cos (500 \mathrm{~mL})$, lactantes $(1,600-2,000 \mathrm{~mL})$ y adultos.

- Toma de oxígeno correspondiente.

- Tru-cut o agujas para acceso intraóseo 14 a 18 G.

- Jeringas desechables de 1, 5, 10, $20 \mathrm{~mL}$.

- Sondas nasogástricas: 6 a 14 G.

- Llave de tres vías.

- Equipo quirúrgico para la colocación de catéteres centrales.

- Catéteres centrales: 4, 5.5 y 7 de 3 lúmenes.

- Sondas de Silastic 14 y 16 FR.

- Sondas urinarias pediátricas 8, 10, 12 FR.

- Bolsas recolectoras de orina.

- Carro rojo:

- Heparina: 1 frasco.

- Adrenalina: ámpulas de 1/1,000 (1 mL = 1 mg).

- Bicarbonato:1 frasco $50 \mathrm{~mL}(1 \mathrm{~mL}=1 \mathrm{mEq})$.

- Atropina: ámpulas de $1 \mathrm{mg}(1 \mathrm{~mL}=1 \mathrm{mg})$.

- Diazepam: ámpulas $10 \mathrm{mg} / 2 \mathrm{~mL}(1 \mathrm{~mL}=5 \mathrm{mg})$.

- Midazolam: ámpulas $15 \mathrm{mg} / 3 \mathrm{~mL}(1 \mathrm{~mL}=5 \mathrm{mg})$.

- Propofol: frasco de $50 \mathrm{~mL}(200 \mathrm{mg} / 20 \mathrm{~mL}, 1$ $\mathrm{mL}=10 \mathrm{mg}$ ).

- Vecuronio: ámpulas de $4 \mathrm{mg} / 1 \mathrm{~mL}$.

- Amiodarona: ámpula de $3 \mathrm{~mL} / 150 \mathrm{mg}$ (1 $\mathrm{mL} / 50 \mathrm{mg}$ ).

- Adenosina: $100 \mathrm{mg} / 10 \mathrm{~mL}$ ( $1 \mathrm{~mL} / 10 \mathrm{mg})$.

- Furosemida: ámpulas de $20 \mathrm{mg} / 2 \mathrm{~mL}(1 \mathrm{~mL}=$ $10 \mathrm{mg}$ ).

- Arterenol: ámpula de $4 \mathrm{mg} / 4 \mathrm{~mL}(1 \mathrm{~mL}=1 \mathrm{mg})$.

- Dobutamina: frasco de $250 \mathrm{mg} \mathrm{(20} \mathrm{mL/250} \mathrm{mg,}$ $1 \mathrm{~mL}=12.5 \mathrm{mg}$ ).

- Dopamina: ámpula de 200 mg/5 mL (1 mL/40 mg).

- Gluconato de calcio: ámpula de $1 \mathrm{~g} / 10 \mathrm{~mL}$ (1 $\mathrm{mL} / 100 \mathrm{mg}$ ).

- Hidrocortisona: ámpulas de 10 mg/2 mL (1 $\mathrm{mL} / 5 \mathrm{~mL}$ ).

- Metilprednisolona: ámpulas de 500 mg/8 mL (1 $\mathrm{mL}=62.5 \mathrm{mg}$ ).

- Lidocaína simple 2\%: frasco de 50 mL (2 g/100 $\mathrm{mL}, 1 \mathrm{~mL}=20 \mathrm{mg}$ ).

- Sulfato de magnesio: ámpula de $1 \mathrm{~g} / 10 \mathrm{~mL}$ (1 $\mathrm{mL}=100 \mathrm{mg}$ ).

- Dextrosa 50\%: frasco de $50 \mathrm{~mL}(1 \mathrm{~mL} / 0.5 \mathrm{~g})$.
Dentro de lo posible, contar con:

- Succinilcolina: ámpula de $2 \mathrm{~mL}=100 \mathrm{~g}$.

- Naloxona: ámpulas de $1 \mathrm{~mL}=0.4 \mathrm{mg}$.

- Flumazenil: ámpulas de $10 \mathrm{~mL} / 1 \mathrm{mg}$.

- Isoproterenol: ámpulas de $1 \mathrm{~mL} / 1.5 \mathrm{mg}$.

- Mascarillas laríngeas pediátricas: \#1, 1.5, 2, $2.5,3,4$.

- Circuitos cerrados de aspiración.

- Guía metálica para intubación.

5. Sala de cambiado, lavado y desinfección: se utiliza para el vestido y desvestido del personal con las medidas higiénicas necesarias para atender un paciente con COVID-19:

- Batas desechables impermeables.

- Pijamas desechables impermeables.

- Guantes no estériles.

- Gorros desechables.

- Cubrezapatos desechables.

- Gafas protectoras.

- Tarja para lavado de manos.

- Tarja con cloro a 1\% para el lavado de gafas protectoras.

- Botes con bolsas rojas para desechos.

- Gel antibacterial.

\section{Criterios de alta hospitalaria}

El virus SARS-CoV-2 puede ser detectado de uno a dos días en la vía respiratoria superior y puede persistir de 7 a 12 días en casos moderados y hasta dos semanas en casos graves. Se ha observado la diseminación prolongada del virus en niños convalecientes después de infecciones leves: en muestras del tracto respiratorio, hasta en 22 días y, en heces, de dos semanas a un mes. ${ }^{3-5}$ Es importante mencionar que la RT-PCR detecta material genético viral que no es necesariamente infeccioso, por lo que estos datos sugieren una disminución del riesgo de contagio de los pacientes en relación con el tiempo de evolución de la enfermedad. ${ }^{5,6} \mathrm{La}$ transmisión por vía fecal no ha sido clara, por lo que los pacientes deberán seguir las precauciones de higiene personal para proteger a los contactos del hogar y disminuir el riesgo de contagio. Por todo ello, es importante enfatizar a los pacientes las medidas de prevención. ${ }^{3}$

En el INER, los pacientes que en su primera revisión se encuentren en estado asintomático con 
contactos confirmados, o bien que presenten sintomatología leve y sean candidatos para manejo ambulatorio, recomendamos realizar el seguimiento por vía telefónica a las 24 y 72 horas, y a los 7 y 14 días de iniciada la sintomatología, con la finalidad de vigilar la evolución mediante la confirmación de los siguientes datos: presencia de fiebre, cefalea, rinorrea, tos, disnea, cianosis, tolerancia a la vía oral, náusea, vómito, dolor abdominal, diarrea, sintomatología en algún otro familiar y si han cumplido el aislamiento. También valoramos en cada llamada el estado emocional del paciente y del cuidador, haciendo énfasis en los datos de alarma y en las recomendaciones de autocuidado durante el aislamiento en casa.

En caso de detectar algún dato de alarma o evolución clínica tórpida mediante el seguimiento telefónico, es necesario citar al paciente a revaloración.

En caso de alta en pacientes hospitalizados sintomáticos, con comorbilidades previas y que cuenten con prueba confirmatoria para COVID-19, sugerimos valorar el alta de acuerdo con las siguientes recomendaciones:

1. Criterios de laboratorio: con el propósito de finalizar el aislamiento, se podrán realizar dos muestras de RT-PCR respiratorio mediante hisopado nasofaríngeo u orofaríngeo, de modo que se demuestre negativización con una separación mínima de 24 horas. No obstante, no es estrictamente necesario para el alta médica y dichas pruebas se realizarán según la capacidad de recursos hospitalarios. ${ }^{7,8}$

2. Criterios clínicos: $\mathrm{SpO}_{2}$ mayor a $90 \%$ con una $\mathrm{FiO}_{2}$ de $21 \%$, ausencia de fiebre $48-72$ horas sin uso de antipiréticos, tolerancia a la vía oral, resolución de síntomas respiratorios o la resolución hospitalaria de alguna otra comorbilidad que presente el paciente y que haya puesto en riesgo su vida. . $^{3,8,9}$ EI CDC considera que los criterios de alta de un paciente con COVID-19 deberán ser: 72 horas de remisión de fiebre sin uso de medicamentos antipiréticos y mejora de los síntomas como disnea y tos, sin que se requiera tener una prueba negativa. ${ }^{8}$

3. Criterios radiológicos: imágenes radiológicas que muestren la reducción o, al menos, la no progresión de áreas de consolidación.?

Los pacientes egresados deberán continuar con aislamiento en casa, por lo que es imprescindible exponer de manera detallada la normativa de aislamiento y las medidas de higiene personal. ${ }^{3,9}$
Una vez egresados, se sugiere realizar el seguimiento telefónico ya comentado. Para los pacientes que ingresaron y se recuperaron en menos de siete días, se deberán evaluar clínicamente en un intervalo de siete días posteriores. ${ }^{3}$

Puntos críticos:

- Mediante RT-PCR, se ha documentado la presencia de virus SARS-CoV-2 en personas asintomáticas, por lo que es necesario que se haga énfasis al paciente para que continúe con medidas de prevención a fin de evitar la transmisión viral. ${ }^{3}$

- Hay un claro beneficio en tomar muestra en pacientes asintomáticos después del aislamiento; sin embargo, el muestreo de personas sintomáticas debería tener prioridad sobre los pacientes asintomáticos después del aislamiento, esto de acuerdo con la disponibilidad de recursos en la institución en la que se encuentren. ${ }^{3}$

- La presencia del virus en heces, si bien no indica que es directamente infeccioso, sugiere una ruta de transmisión fecal-oral. ${ }^{7}$ Sin embargo, no se requerirá negativización del virus en otras muestras como orina o heces para el alta del paciente. Esto debe tenerse en cuenta a la hora de establecer las medidas higiénicas recomendadas al alta. ${ }^{3}$

\section{RECOMENDACIONES PARA EL CUIDADO DOMICILIARIO}

Fuera del ámbito hospitalario, existen recomendaciones y medidas que deben ser compartidas a los familiares y que se deben seguir para evitar el contagio a los contactos domiciliarios. En nuestro instituto, realizamos una presentación en video para poder compartirlo mediante un link, o bien mediante una fotografía que el familiar toma antes de irse a casa, ya que no es adecuado compartir material impreso por el riesgo de transmisión.

\section{Recomendación para pacientes ${ }^{10}$}

- Mantener contacto con el personal de salud todo el tiempo que dure el aislamiento. Puede ser por vía telefónica.

- Monitorear la temperatura corporal al menos dos veces al día.

- Todas las superficies que se ensucien con secreciones respiratorias o líquidos corporales del 
paciente deben ser limpiadas y desinfectadas con una solución de cloro diluido. Ésta se prepara diluyendo $100 \mathrm{~mL}$ de cloro comercial más $900 \mathrm{~mL}$ de agua (concentración final de $0.5 \%$ de hipoclorito de sodio).

- Ubicar al paciente en una habitación bien ventilada y, de ser posible, solo; mantener la puerta cerrada hasta la finalización del aislamiento.

- Limitar el movimiento del paciente fuera del cuarto y minimizar el espacio compartido. Asegurarse de que los espacios compartidos estén bien ventilados.

- No tocar ojos, boca y nariz.

- Evitar el contacto directo con líquidos corporales como secreciones respiratorias o de boca, materia fecal, orina u otros desechos generados por personas enfermas. Usar guantes desechables cuando pueda haber contacto con estos líquidos, y realizar higiene de manos antes y después de retirarse los guantes.

- Las superficies tocadas con frecuencia, como mesas de noche, cabecera de la cama y otros muebles del dormitorio, se deben limpiar y desinfectar una vez al día. Hay que hacerlo con una solución de cloro a $0.5 \%$.

- Si es posible, se dispondrá de un baño para uso exclusivo del paciente, o en su defecto, deberá ser limpiado con lejía doméstica tras cada uso que haga el paciente.

- Hay que limpiar y desinfectar las superficies del baño y el inodoro al menos una vez al día con la solución de cloro diluido a la concentración comentada.

- Evitar el contacto directo de la piel con ropa contaminada del enfermo, y colocarla en una bolsa. Hay que evitar agitar la ropa sucia o sacudir las sábanas. Procure lavar la ropa de cama, toallas de baño y toallas de mano de la persona enferma con detergente regular y agua, o en lavadora con agua a 60 a $90^{\circ} \mathrm{C}$ de ser posible; de lo contrario, con agua fría.

- Se deben usar guantes desechables y ropa protectora cuando se limpien o manejen superficies o ropa sucia con líquidos corporales.

- Las personas con síntomas deben permanecer en casa por 14 días.

- Desechar pañuelos o cubrebocas usados para cubrir la boca o la nariz, o bien limpiarlos apropiadamente después de su uso (sólo en caso de pañuelos de tela).

- Los guantes, pañuelos, cubrebocas y otros desechos generados por personas enfermas deben ser colocados en una bolsa dentro de un contenedor (bote) con tapa; la bolsa debe cerrarse antes de sacarla de la habitación de la persona enferma. Esta bolsa deberá marcarse como residuos sanitarios. Deberá rociarse por dentro y por fuera con una solución de agua clorada y posteriormente entregarse al camión o persona que recolecta la basura. ${ }^{4}$

\section{Uso de cubrebocas quirúrgico}

- El cuidador debe usarlo cuando esté en la misma habitación con la persona enferma, verificando que le cubra nariz y boca.

- El cubrebocas no debe tocarse ni manipularse durante su uso.

- Si se humedece o ensucia con secreciones, debe cambiarse inmediatamente.

- Después de usarlo, es necesario que se deseche y posteriormente realizar higiene de manos.

\section{Higiene de manos}

Es un procedimiento que debe realizarse después de todo contacto con personas enfermas o su medio ambiente inmediato, antes y después de preparar alimentos, antes de comer, después de usar el baño, y cuando las manos se vean sucias. Debe realizarse con agua y jabón, abarcando las palmas, los dorsos de las manos, los espacios interdigitales, los pulgares, los nudillos, las uñas y las muñecas; el proceso debe durar por lo menos 20 segundos. Es deseable que se usen toallas de papel desechables para secar las manos; si no están disponibles, usar toallas de tela exclusivas para el enfermo y reemplazarlas cuando estén húmedas.

Si las manos no están visiblemente sucias, se puede frotar con alcohol en gel a $70 \%$, siguiendo los mismos pasos hasta que las manos estén secas. El paciente debe realizar higiene de manos frecuentemente.

\section{Recomendaciones para contactos ${ }^{11}$}

- El médico deberá estar enterado del estado de salud o aparición de síntomas de los contactos del paciente (fiebre, cefalea, tos, ataque al estado general y disnea).

- Limitar el número de cuidadores del paciente, idealmente asignar a una persona con buena salud, sin condiciones de riesgo y evitar visitas extras. 
Rev Latin Infect Pediatr 2020; 33 (s1): s75-s95

- No debería haber convivientes con condiciones de salud que supongan una vulnerabilidad (tercera edad, enfermedades crónicas como diabetes e hipertensión, inmunodepresión y embarazo).

- Todos los miembros del hogar, incluyendo quienes trabajan en él, se consideran contactos. Se aconseja vigilar su estado de salud por 14 días desde el último día del último contacto, y buscar atención médica inmediata si desarrollan síntomas.

- Si un contacto presenta síntomas, debe utilizar cubrebocas para buscar atención médica. Si es posible, evitar el transporte público. También, si es posible, abrir las ventanas del vehículo.

- El contacto que desarrolle síntomas debe realizar siempre higiene respiratoria y de manos, y permanecer a $1.5 \mathrm{~m}$ de distancia de otras personas cuando se transporte y cuando llegue al centro de atención médica. El término higiene respiratoria se refiere a cubrir la boca y nariz durante la tos o el estornudo, usando cubrebocas, pañuelos o el codo flexionado y en seguida, realizar higiene de manos.

- Los miembros del hogar deben permanecer en una habitación diferente o, si esto no es posible, mantener una distancia de al menos un metro de la persona enferma. Una excepción a esto puede ser considerada en una madre que esté lactando. La madre debe usar cubrebocas quirúrgico y tener higiene de manos cuidadosa.

- En caso de ser el cuidador primario de un niño menor de cinco años, puede quedarse con él, utilizando cubrebocas y lavarse o desinfectarse las manos con frecuencia. Se recomienda desinfectar frecuentemente las manos de menores de cinco años.

- Evitar otras formas de posible exposición a objetos contaminados de la persona enferma (cepillo de dientes, cigarros, cubiertos, platos, bebidas, toallas o ropa de cama). Los cubiertos y platos deben lavarse con agua y jabón o detergente después de uso, y se pueden reutilizar.

\section{CUIDADOS DE ENFERMERÍA}

Es importante señalar que las fuentes de información citadas como referencia en este documento están en continua revisión para alinear sus contenidos de acuerdo con la evolución epidemiológica de la situación, por lo que es recomendable consultarlas continuamente.
El objetivo esencial de esta revisión es aportar sugerencias y recomendaciones al profesional de enfermería para proporcionar el cuidado del paciente pediátrico con sospecha y/o infección por SARS-CoV-2; algunas de estas recomendaciones van desde aquel paciente que no es necesario hospitalizarlo hasta aquel que, por su gravedad, se hace acreedor a una serie de cuidados más complejos que realizan tanto el profesional de enfermería como el equipo de salud.

\section{Recomendaciones generales}

Siguiendo las instrucciones de los documentos de referencia de las autoridades sanitarias, se recomienda la colocación de información visual (por ejemplo, carteles y folletos) en las salas de espera, donde se debe incluir información adaptada para los pacientes pediátricos, de modo que se advierta y ofrezca a los niños con edad suficiente o a los familiares la información para que puedan colaborar y las instrucciones sobre el lavado de manos e higiene respiratoria (incluyendo protección con la flexión del codo al toser o estornudar, llamado de «etiqueta»). Para los niños pequeños, serán los padres y/o familiares que los acompañan los que enseñen esa información a cabo, tanto a sí mismos como a los niños.

Es importante considerar que los niños de menor edad presentan características que dificultan el control de las infecciones y que pueden facilitar el contagio, por ejemplo:

- No controlan la emisión de las secreciones y excreciones, esto es, salivación, babeo y ausencia de control de esfínteres.

- Presentan incomodidad para mantener la mascarilla quirúrgica sobre nariz y boca. En menores de un año, no se recomienda usarla.

- Se les dificulta poder controlar sus desplazamientos y permanecer quietos en un lugar determinado, lo que imposibilita el control de los contactos adecuadamente.

- Tienen una tendencia a compartir juguetes y objetos e interaccionar entre ellos, por lo que se recomienda evitar el ingreso a hospitalización con algún juguete.

Por ello, hacemos las siguientes recomendaciones:

- Los pacientes pediátricos que acudan a valoración con síntomas de infección respiratoria aguda 
deben recibir y colocarse una mascarilla quirúrgica, si es posible.

- En las salas pediátricas de espera no habrá materiales como juguetes, libros u otros utensilios en los que no se pueda garantizar que se cumplen las normas de limpieza e higiene de material recomendadas.

- En los niños mayores de 1 año que no toleren la mascarilla quirúrgica, se deben mantener aislados, al menos, dos metros del resto de pacientes.

- Todos los acompañantes de los niños con o sin síntomas de sospecha de COVID-19 u otra infección respiratoria deberán utilizar mascarilla quirúrgica.

- Al ingresar a la sala de espera, los acompañantes y/o familiares deberán facilitar y ayudar a los niños a utilizar adecuadamente la solución hidroalcohólica que estará a su alcance. Se deberá advertir que no debe ser ingerida ni entrar en contacto con los ojos.

- Los niños y/o familiares que puedan ser considerados, por clínica y epidemiología, como casos sospechosos de infección o hayan sido contacto de pacientes con COVID-19 deberán ser aislados en el área que se ha designado para tal efecto.

\section{Equipo de protección recomendado para el personal de enfermería para la atención del paciente con COVID-19}

La Asociación Argentina de Pediatría, al igual que el INER, considera que el personal de enfermería debe tener disponible para la atención del paciente y su seguridad el EPP, además de realizar higiene de manos antes y después del contacto con todo paciente. El EPP para el personal de enfermería consiste en:

- Respirador N-95.

- Gorro.

- Guantes.

- Gafas protectoras cerradas.

- Bata impermeable.

- Botas o cubrezapato.

\section{Medidas durante la hospitalización}

- Se recomienda que el paciente se mantenga en una habitación individual aislada. No podrá salir a las áreas comunes de las instalaciones, las visitas serán restringidas y éstas deberán usar en todo momento la protección adecuada. ${ }^{1}$

- Se evitará el traslado del paciente entre distintas áreas del hospital. Sólo se realizará en caso necesario y, en todo momento, el paciente deberá utilizar mascarilla quirúrgica. El personal que lo traslade deberá protegerse previamente.

- Se restringirá el número de personal sanitario que acceda a las instalaciones y habitaciones designadas. Las entradas deberán estar programadas; también es necesario contemplar y organizar con antelación qué necesidades habrá en el interior para evitar entradas innecesarias.

- Se cumplirá una estricta higiene de manos antes y después del contacto con el paciente y posterior a la retirada del EPP. El material debe ser de un solo uso.

- Todo el personal sanitario debe utilizar los elementos de protección adecuados según el riesgo de exposición a pacientes sospechosos o confirmados con COVID-19 y a la dinámica de transmisión del patógeno que asigne cada institución.

- Se debe contemplar que los pacientes pediátricos requieren acompañamiento, habitualmente del padre o madre, al cual se le debe instruir en las medidas de prevención de diseminación de la infección: higiene de manos, higiene respiratoria, uso de EPP y pautas de conducta, como restricción de movimientos y restricción estricta de visitas. El acompañante es considerado como un contacto estrecho. Cuando las circunstancias lo permitan, es recomendable que dicho acompañante sea siempre la misma persona durante todo el proceso asistencial.

\section{Lavado de manos y aseo personal}

El lavado de manos es una de las acciones principales para evitar el contagio por coronavirus, el cual se tiene que realizar en los siguientes momentos:

- Tras el contacto con saliva, secreciones oculares y nasales, la manipulación de pañuelos, y antes y después del cambio de pañal.

- Después de toser o estornudar.

- Antes y después de cada contacto que se haga con el paciente.

- Antes de comer.

- Después de realizar la limpieza de cualquier útil o superficie. No compartir con los demás alimentos, bebidas, vasos, platos y cubiertos.

\section{Limpieza}

El personal de limpieza deberá portar el EPP para realizar las siguientes tareas: 
Rev Latin Infect Pediatr 2020; 33 (s1): s75-s95

- Mantener limpias las superficies de uso frecuente: mesas, teclados, teléfonos, manijas de las puertas, es decir, todas las áreas tocadas a menudo, así como todas las superficies accesibles de paredes y ventanas, grifos, la taza del inodoro y el baño. Asimismo, cualquier objeto con el que el paciente tenga contacto para su posterior limpieza. ${ }^{1}$

- Vigilar y poner especial atención a las superficies que puedan tener sangre, heces o fluidos corporales.

- Se dispondrá de un bote de basura con tapa y bolsa roja en su interior con cierre hermético para alojar cualquier deshecho.

- La desinfección de superficies se sugiere con hipoclorito de sodio a $0.05 \%$ (para limpieza habitual) y a $0.5 \%$ en caso de salpicadura de materiales biológicos. ${ }^{12}$

\section{SITUACIONES ESPECIALES EN LA UNIDAD DE CUIDADOS INTENSIVOS}

Se debe utilizar el EPP cuando se cuida a niños con COVID-19.

Los procedimientos que generen aerosoles son de alto riesgo y se requiere un EPP. Dichos procedimientos deben reducirse al máximo. Éstos son:13

- Intubación y/o ayuda durante la intubación.

- Extubación.

- Aspiración traqueal (sin sistema cerrado).

- Ventilación con bolsa-válvula-mascarilla.

- Ventilación mecánica no invasiva, sin sellado adecuado.

- Tos/estornudos o cualquier procedimiento que los induzca.

- Cánula nasal de alto flujo.

- Administración de medicamentos nebulizados.

- Reanimación cardiopulmonar (antes de la intubación).

- Cualquier procedimiento que pueda conllevar la desconexión del circuito del ventilador (pronación).

Para ello, se hacen las siguientes recomendaciones:

- Suspender de la fisioterapia respiratoria de rutina.

- Utilizar el EPP completo si existe algún riesgo de aerosoles.

- Utilizar siempre un sistema de aspiración cerrado.

- Evitar cambiar el sistema de aspiración a menos que esté sucio/contaminado.

- Evitar la desconexión del circuito de ventilación.
- Revisar el globo del tubo endotraqueal cada 6 a 12 horas para comprobar que no haya fugas y que la presión sea segura $\left(<20 \mathrm{cmH}_{2} \mathrm{O}\right)$.

- Si está indicada la pronación, considerarla cada 12 horas al día (evitar la desconexión).

- Minimizar la higiene oral a cada 12 horas (procedimiento de alto riesgo).

- Alimentar por vía enteral según tolere el paciente y evitar las áreas de presión.

- No utilizar nebulizaciones y, en caso de requerirse, aplicar en MDI con un conector al circuito de ventilación (con EPP completo). Si el paciente está extubado, aplicar el MDI con una cámara espaciadora por los padres al paciente.

- Si el paciente está con CPAP/VNI, asegurar que la mascarilla está bien sellada y que no tenga fugas.

- No agitar la ropa o sábanas para no generar aerosoles.

- La situación clínica del paciente debe ser monitorizada de manera continua.

Se tratará de evitar las complicaciones como:

- Tromboembolismo pulmonar: anticoagulación profiláctica.

- Infección por catéter; tener presente los protocolos del programa «Bacteriemia Cero».

- Neumonías asociadas con ventilación mecánica: considerar protocolo de «Neumonía Cero».

- Lesiones por presión (iatrogénicas, por dispositivos, por humedad, por presión, por adhesivos y úlceras corneales).

- Miopatía del paciente crítico: movilización pasiva, activa y precoz.

Para su aplicación, deberán tomarse en cuenta las características propias de las organizaciones de salud, tales como su infraestructura, logística y los recursos humanos con los que se cuenta. Los protocolos que se implementen deben contribuir a prevenir, proteger y mantener la seguridad del equipo de salud durante su labor, a través de la capacitación y retroalimentación constante. De igual modo, se debe contar con el EPP y proporcionar los cuidados de enfermería correspondientes a los pacientes pediátricos con COVID-19.

\section{EQUIPO DE PROTECCIÓN PERSONAL (EPP)}

En las epidemias de enfermedades altamente infecciosas, por ejemplo, la enfermedad por el virus 
del Ébola (EVE) o SARS-CoV, y en este caso la enfermedad por SARS-CoV-2, los TAS tienen un riesgo mucho mayor de infección que la población general, debido al contacto con secreciones y los líquidos orgánicos contaminados de los pacientes. Las precauciones de contacto por medio del EPP pueden reducir el riesgo. ${ }^{14}$

EI EPP tiene como objetivo mejorar la seguridad del personal en el entorno sanitario a través de su uso apropiado, ${ }^{15}$ pues evita el contacto del agente infeccioso al crear una barrera entre el trabajador y el material infeccioso, tal como se ilustra en la Figura 1. La institución donde se labora debe establecer protocolos sobre qué elementos constituye el EPP para cada empleado, ya que éstos pueden variar según la función que se desempeñe.

Debemos contemplar tres puntos al elegir el EPP: ${ }^{16}$

- Tipo de exposición anticipada: exposición de contacto, aerosoles, sangre o fluidos corporales.

- Durabilidad y la idoneidad para la tarea.

- Tener un tamaño adecuado, ya que debe ajustarse de manera individual.

\section{Guantes}

Los guantes protegen contra el contacto de materiales infecciosos. Sin embargo, una vez contaminados, pueden convertirse en un medio de propagación de materiales infecciosos para el personal de la salud, otros pacientes o superficies ambientales. Por lo tanto, la forma en que se usan puede influir en el riesgo de transmisión de enfermedades dentro del entorno de atención médica (Figura 2). ${ }^{16}$

Reglas para el uso de guantes: ${ }^{: 16}$

- Trabajar de «limpio a sucio».

- No tocarse la cara y no ajustar el EPP con guantes contaminados.

- No tocar las superficies, excepto cuando sea necesario en el cuidado del paciente.

- Cambiar de guantes en cuanto sea necesario: cuando se rasguen o estén muy sucios; asimismo, cambiar de guantes entre cada paciente, y desecharlos en el recipiente apropiado.

- Nunca lave o reutilice guantes desechables, pues puede que no sea posible eliminar todos los microorganismos y que los guantes sean más propensos a fuga.

\section{Batas}

Factores que influyen en la selección de batas (Figura 3): ${ }^{16}$

- Propósito de su uso: las batas de aislamiento son generalmente las establecidas en el EPP.

- Propiedades del material de la bata. Las batas de aislamiento están hechas de algodón o algún material sintético hilado.

- Riesgos del paciente: las batas limpias (no estériles) generalmente se usan para aislamiento y las batas estériles sólo son necesarias para realizar procedimientos invasivos.

\section{Respiradores}

Factores que influyen en la selección de respiradores (Figura 4): ${ }^{16}$

- Los respiradores recomendados son los de partículas N95, N99 o N100, que tienen un filtro submicrométrico capaz de excluir partículas de menos de 5 micras de diámetro.

- Deben estar aprobados por el NIOSCH/CDC.

\section{Gafas protectoras}

Factores que influyen en la selección de gafas (Figura 5): ${ }^{16}$

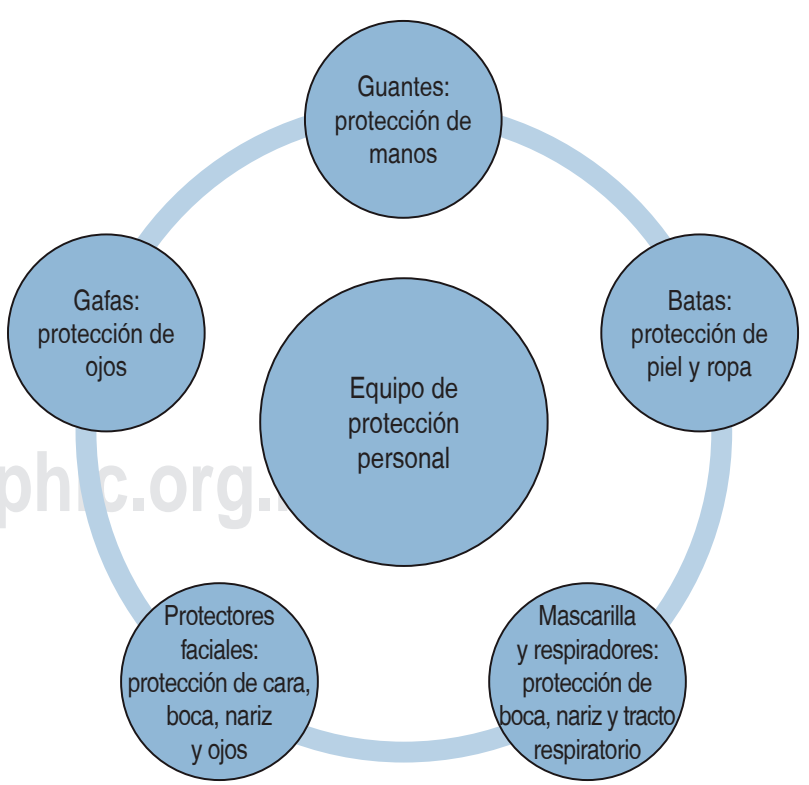

Figura 1: Muestra las barreras de protección que conforman el equipo de protección personal (EPP). 


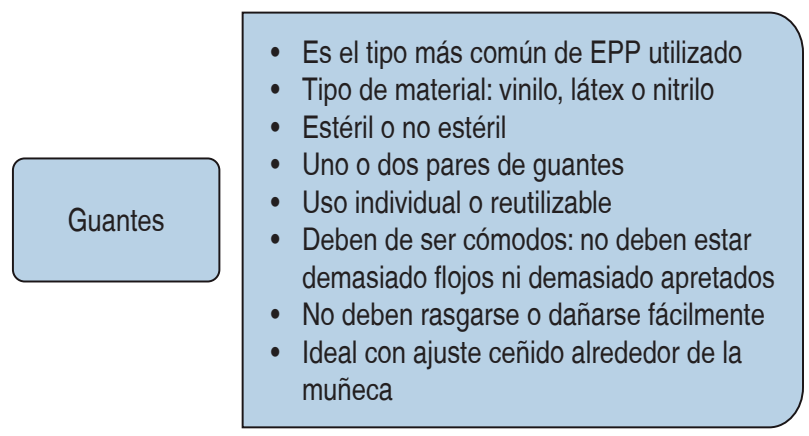

Figura 2: Características de los guantes.

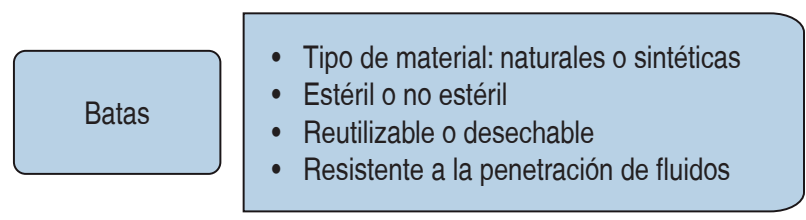

Figura 3: Características de las batas.

- Las gafas deben ajustarse cómodamente sobre y alrededor de los ojos, o usar lentes recetados personales.

- Las gafas con función antiempañante ayudarán a mantener la claridad de la visión.

- Se recomienda que sean gafas protectoras cerradas.

\section{Protectores faciales}

Factores que influyen en la selección de protectores faciales (Figura 6): ${ }^{16}$

- El protector facial debe cubrir la frente, extenderse debajo de la barbilla y envolverse alrededor del lado de la cara.

- Se puede usar un protector facial como sustituto del uso de un respirador y/o gafas protectoras, cuando éstos tienen un purificador de aire instalado.

El uso de escafandras dependerá de los recursos económicos y disponibilidad de cada institución, al igual que el uso de gorros. Igualmente, sugerimos el uso de cubrezapatos o botas como parte del EPP.

La colocación y retiro del EPP puede variar según las normas de cada país o de cada institución. A continuación, mencionaremos las recomendaciones en orden del CDC con algunas sugerencias importantes.

\section{Colocación del EPP ${ }^{16}$}

1. Colocación de la bata: seleccione la bata y talla adecuada para la tarea. La apertura de la bata debe estar en la espalda; amárrela en la parte posterior del cuello y la cintura. Si la bata es demasiado pequeña para cubrir completamente su torso, use dos batas, poniéndose la primer bata con la abertura al frente y la segunda sobre la primera con la abertura en la espalda.

2. Colocación del respirador: colóquela sobre su boca, nariz y mentón. Ajuste la pieza nasal flexible a la forma de su puente nasal; acomode la banda elástica superior en la parte posterior de su cabeza y la inferior debajo de las orejas en la base del cuello. Ajuste la máscara. Realice una comprobación de ajuste: inhale, el respirador debe colapsar; exhale y verifique si hay fugas alrededor de la cara.

3. Colocación de las gafas o el protector facial: coloque cualquiera de los dispositivos sobre la cara y/o los ojos y asegúrelo a la cabeza utilizando la banda diseñada para ello. Ajústelo para adaptárselo cómodamente. Las gafas deben sentirse ajustadas, pero no apretadas.

4. Colocación de los guantes: asegúrese de seleccionar el tipo de guante necesario para la tarea en el tamaño que mejor se adapte a usted. Inserte cada mano en el guante apropiado y ajústelo según sea necesario para mayor comodidad y destreza. Si usa una bata de aislamiento, meta los puños de la bata de forma segura debajo de cada guante.

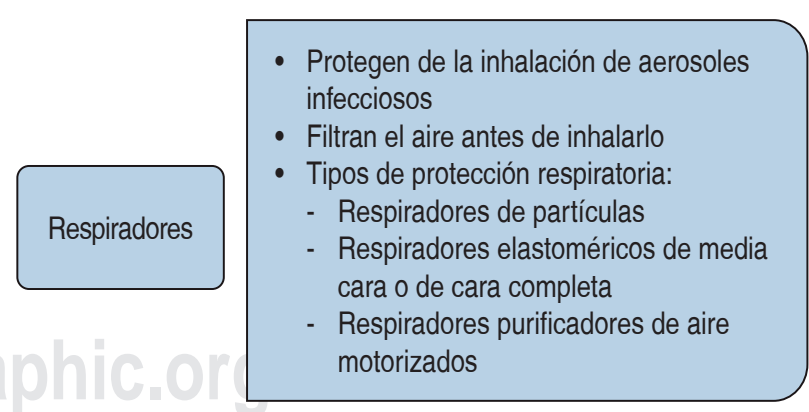

Figura 4: Características de los respiradores.
Gafas protectoras
- Protegen los ojos

- Las gafas personales no son un sustituto de las gafas protectoras
Figura 5: Características de las gafas protectoras. 
Protectores faciales

Figura 6: Características de los protectores faciales.

\section{Retiro del EPP ${ }^{16}$}

Consideramos importante mencionar que el proceso de retiro debe hacerse con calma, además de ser supervisado por otro miembro del equipo para evitar la contaminación.

1. Retiro de los guantes: usando una mano enguantada, tome el exterior del guante opuesto cerca de la muñeca. Tire y jale el guante lejos de la mano. El guante ahora debe estar al revés, con el lado contaminado ahora adentro. Sostenga el guante quitado en la mano enguantada opuesta. Deslice uno o dos dedos de la mano sin guantes debajo de la muñeca del guante restante. Despéguelo desde adentro, creando una bolsa para ambos guantes. Finalmente, deséchelos en el contenedor de residuos.

2. Retiro de las gafas: con las manos sin guantes, agarre las orejas o cabezales y levántelos de la cara. Si las gafas o el protector facial son reutilizables, colóquelos en un receptáculo designado para el reprocesamiento posterior (sugerimos que se coloquen en una solución de hipoclorito a 10 $0.5 \%$, posteriormente que se laven con agua y jabón para quitar el excedente de color y dejar secar). De lo contrario, deséchelos en el contenedor de residuos.

3. Retiro de la bata: desabroche los lazos de la bata y deslice las manos por debajo de la bata en el cuello y el hombro; despegue de los hombros. Deslice los dedos de una mano debajo del brazalete del brazo opuesto. Tire de la mano dentro de la manga, agarrando la bata por dentro. Alcance y empuje la manga del brazo opuesto. Doble la bata hacia el interior y doble o enrolle en un paquete (sólo debe verse la parte «limpia» de la bata). Deseche en un contenedor de desechos o ropa blanca, según corresponda.

4. Retiro del respirador: el frente de la máscara se considera contaminado y no debe tocarse. El elástico inferior debe levantarse primero sobre la cabeza y luego retire el elástico superior. Levante la máscara o respirador lejos de la cara.

5. La higiene de las manos es la piedra angular para prevenir la transmisión de infecciones. Debe realizar la higiene de manos inmediatamente después de quitarse el EPP. Si sus manos se contaminan visiblemente durante la eliminación del EPP, lávese las manos antes de continuar con el retiro del EPP.

\section{MANEJO DE RESIDUOS BIOLÓGICOS INFECCIOSOS}

El objetivo de este apartado es conocer la clasificación de los residuos peligrosos biológico-infecciosos (RPBI), así como las especificaciones para su manejo.

Las buenas prácticas para el manejo de desechos derivados de la atención médica consideran que debe ser seguro, tanto para el que lo hace como para el medio ambiente. Se deben clasificar los desechos de acuerdo con las normativas del Estado, del territorio y la Legislación Nacional. ${ }^{17}$ En México, se realiza de acuerdo con la Norma Oficial Mexicana NOM087-ECOL-SSA1-2002, mediante la concentración de empresas autorizadas por la SEMARNAT para la recolección, traslado y tratamiento de los residuos biológicos-infecciosos. ${ }^{18,19}$

El riesgo de los trabajadores por la exposición ocupacional al SARS-CoV-2 puede variar de un riesgo muy alto a uno alto, medio o bajo. El nivel de riesgo depende de la necesidad de contacto a menos de $1.5 \mathrm{~m}$ y del contacto repetido o prolongado de personas que se conocen o se sospecha que están infectadas con SARS-CoV-2. De acuerdo con esta clasificación, el personal encargado de la recolección o manejo de los residuos biológicos-infecciosos entra en el grupo de alto riesgo y muy alto riesgo, por lo que se considera que deben usar el EPP de acuerdo con las especificaciones mencionadas en capítulos anteriores, adicionando trajes médicos/quirúrgicos, overoles resistentes a fluidos, delantales o alguna otra vestimenta de protección ${ }^{20}$ asignada por su institución.

No hay evidencia de que el contacto humano directo y sin protección durante el manejo de los desechos sanitarios haya resultado en la transmisión del virus causante de la infección por SARS-CoV-2; sin embargo, todos los residuos biológicos producidos durante el diagnóstico y tratamiento, tanto de pacientes sospechosos como confirmados, requiere de medidas específicas: deben ser recolectados de 
Rev Latin Infect Pediatr 2020; 33 (s1): s75-s95

manera segura en contenedores y bolsas designados, tratados y luego desechados de forma segura. ${ }^{5,6}$

También hay que tener en cuenta que todos los tipos de EPP deben:

- Seleccionarse con base en el riesgo para el trabajador.

- Ajustarse apropiadamente y verificar su ajuste periódicamente.

- Usarse de manera consistente y adecuada cuando sea requerido.

- Inspeccionarse y recibir mantenimiento regularmente y, de ser necesario, ser reemplazado.

- Removerse, limpiarse y almacenarse o desecharse de manera apropiada, según sea aplicable, para evitar la contaminación del usuario, de otros, o del ambiente. ${ }^{20}$

\section{Categorías de los contenedores para RPBI}

\section{Color amarillo}

Sin exceder $80 \%$ de su capacidad, en los contenedores amarillos se deben desechar los siguientes residuos:

- Patológicos o anatómicos: pueden ser humanos (por ejemplo, tejidos o biopsias) o animales (procedentes de laboratorio de investigación). Estos deben colocarse en bolsas de plástico de color amarillo, libres de cloro, y conservarse a $4{ }^{\circ} \mathrm{C}$ cuando no se encuentran embebidos en formol.

- Patológicos líquidos: son todas las muestras biológicas utilizadas para el análisis químico, microbiológico, citológico e histológico, excluyendo la orina y el excremento. Deben desecharse en recipientes rígidos de color amarillo, con tapa hermética de polipropileno, libres de cloro, con la leyenda: «Residuos peligrosos líquidos biológicoinfecciosos» y marcados con el símbolo universal de riesgo biológico.

\section{Color rojo}

Sin exceder $80 \%$ de su capacidad, en los contenedores rojos se deben desechar los siguientes residuos:

- Cultivos y cepas de agentes biológicos-infecciosos: los cultivos generados en los procedimientos de diagnóstico e investigación, incluyendo los utensilios desechables usados para contener, transferir, inocular y mezclar estos cultivos. Deben colocarse en bolsas de plástico de color rojo, libres de cloro, y tratarse mediante esterilización en autoclave antes de ser enviado para su disposición final.

- Residuos no anatómicos: recipientes desechables que contengan sangre líquida; materiales de curación empapados, saturados o goteando sangre o fluidos corporales (sinovial, pericárdico, pleural, cefalorraquídeo o peritoneal); materiales desechables que contengan esputo, secreciones pulmonares y cualquier material usado para contenerlos (tubos, mascarillas de oxígeno, catéteres y juegos intravenosos, guantes, jeringas y bolsas de orina). Deben colocarse en bolsas de plástico de color rojo, libres de cloro.

- La sangre y los componentes de ésta, en su forma líquida, así como los hemoderivados, deben desecharse en recipientes rígidos de color rojo, con tapa hermética de polipropileno, libres de cloro, con la leyenda: "Residuos peligrosos líquidos biológico-infecciosos» y marcados con el símbolo universal de riesgo biológico.

- Objetos punzocortantes: aquéllos en contacto con muestras biológicas durante el diagnóstico y tratamiento (tubos capilares, navajas, lancetas, agujas de jeringas desechables, agujas hipodérmicas, agujas de sutura, hojas de bisturí y estiletes de catéter) deben desecharse en recipientes rígidos de color rojo, con tapa hermética de polipropileno, libres de cloro, con la leyenda: «Residuos peligrosos biológico-infecciosos» y marcados con el símbolo universal de riesgo biológico.

\section{Otros residuos}

- Muestras biológicas o excretadas por los pacientes con COVID-19 (orina y excremento): deben tener un tratamiento químico mediante solución de hipoclorito de sodio a 1-2\% durante 30 minutos y después descargarlos en desagües o alcantarillas de manera convencional.

- Artículos como colchones, ropa de cama y equipo médico no contaminados con sangre o fluidos corporales de los pacientes: deben limpiarse utilizando una solución de hipoclorito de sodio a 1-2\%.

Como precaución adicional, se debe usar doble bolsa para la recolección de desechos generados por pacientes con COVID-19, asegurándose del cerrado 
adecuado y buscando evitar fugas. Los carritos y botes específicos para el retiro, así como la entrada y salida de los contenedores de basura deberán ser desinfectados con solución de hipoclorito de sodio a $1 \%$ y ser etiquetados con la leyenda «Desechos de COVID-19» para facilitar su identificación y dar prioridad para su procesamiento. Estos desechos deben mantenerse separados de los que no están contaminados, y su procesamiento será de acuerdo con la legislación correspondiente. ${ }^{21,22}$

\section{RECOLECCIÓN Y MANEJO DE MUESTRAS}

Para fines de transporte y manejo, se entiende por sustancias infecciosas aquéllas que contienen agentes patógenos, los cuales son microorganismos como bacterias, virus, rickettsias, parásitos, hongos y otros agentes como priones, que pueden causar enfermedades en los animales o en los seres humanos. ${ }^{23}$

\section{Clasificación de sustancias infecciosas}

- Sustancia infecciosa categoría A: es capaz de causar una incapacidad permanente, poner en peligro la vida o constituir una enfermedad mortal para seres los humanos o animales previamente sanos.

- Sustancia biológica categoría B: no cumple los criterios para la categoría A; existe una probabilidad de que contenga patógenos.

- Sustancias exentas: presentan un riesgo mínimo de contener agentes patógenos. ${ }^{24}$

\section{Recolección y manejo de muestras}

Las muestras de pacientes sospechosos de SARSCoV-2 son clasificadas como sustancias biológicas categoría B y deben enviarse al InDRE o centros colaboradores en el país. ${ }^{24}$

Para la recolección, transporte y manipulación de muestras dentro de todas las unidades de salud, se debe asegurar que los trabajadores de la salud que recolectan muestras de pacientes con sospecha o confirmación de COVID-19 usen el EPP apropiado. Se colocarán las muestras en bolsas para su transporte, comprobando que no existan fugas, así como que contengan un adecuado sellado; se debe etiquetar la muestra del paciente y llenar un formulario de solicitud de cada institución. Asimismo, es necesario asegurar que el personal que transporta las muestras esté capacitado en prácticas de manejo seguro y en procedimientos de descontaminación de derrames; finalmente, hay que asegurar que los laboratorios en las instalaciones de atención médica cumplan con las buenas prácticas de bioseguridad según el tipo de organismo que se maneja. ${ }^{17}$

Las muestras se transportarán en sistemas de triple embalaje PI 650 (Figura 7), los cuales están constituidos por:

- Contenedor primario impermeable.

- Contenedor secundario impermeable.

- Material absorbente (de humedad e impacto).

- Embalaje externo rígido (transporte aéreo): caras de longitud mínima de $100 \mathrm{~mm}$.

Dichos sistemas deben haber pasado exitosamente la prueba de presión a $95 \mathrm{kPa}$ y la prueba de caída libre de $1.2 \mathrm{~m} .{ }^{24}$

Las muestras deben mantenerse refrigeradas a una temperatura de 4 a $8^{\circ} \mathrm{C}$, y enviarse al laboratorio correspondiente, donde se procesarán dentro de 24 a 72 horas de la toma. Si no se pueden enviar muestras dentro de ese periodo, se recomienda congelarlas a $-70{ }^{\circ} \mathrm{C}$ (o menos) hasta que se envíen, asegurando que se mantenga la cadena de frío. ${ }^{25}$

\section{PROCESAMIENTO DE CADÁVER}

Dentro del contexto de una enfermedad emergente, la defunción de los afectados y su manejo es una preocupación que no debe pasar a segundo plano, pues conlleva implicaciones sociales, emocionales y económicas que, de no ser atendidas con un protocolo de atención integral, pueden entorpecer el sistema de salud e incluso ocasionar mayores problemas al tratarse de una enfermedad infectocontagiosa, como es la actualmente causada por SARS-CoV-2. ${ }^{26,27}$

Si bien hasta ahora no existe una evidencia concreta de que los cadáveres de individuos con diagnóstico confirmado o sospechoso de COVID19 sean una fuente relevante de infección de esta enfermedad, ${ }^{28-32}$ se aplica el principio de precaución para realizar las medidas necesarias y evitar la de transmisión del virus desde el antiguo hospedero al personal sanitario, personal funerario o familiares que vayan a manejar el cadáver. ${ }^{30}$

Dentro del protocolo para el manejo de cadáveres que propone el INER ${ }^{28}$ y la SS ${ }^{29}$ en México, tenemos las siguientes recomendaciones: 
Rev Latin Infect Pediatr 2020; 33 (s1): s75-s95

- Dentro de lo posible, se deben evitar procedimientos invasivos, por lo que las autopsias no se realizarán una vez que se tenga el diagnóstico confirmado o sospechoso de COVID-19 ${ }^{28,32}$ como causa relacionada con el fallecimiento. Otras guías ${ }^{26,30,33,34}$ sugieren medidas necesarias para que, en caso de fuerza mayor, se pueda realizar la autopsia; sin embargo, en el contexto de nuestro país, se valorará la realización de la autopsia con fines de estudio definidos para conocer mejor la fisiopatología, mas no de primera intención. Una opción adecuada que ha sido descrita por organismos internacionales, ${ }^{26,30,33}$ si la intención es corroborar el diagnóstico de COVID-19, es la toma de muestra de secreciones nasofaríngeas o del lavado bronquioalveolar para realizar RT-PCR en el paciente fallecido. Esta toma siempre se debe hacer con las respectivas medidas del uso de EPP para evitar el contagio.

- Para el manejo del cadáver, deben seguirse las recomendaciones generales de lavado de manos con agua y jabón, uso del EPP, ${ }^{28}$ evitar tocarse la cara y evitar ingerir alimentos o agua en el área de manejo de cadáveres. Debe haber un espacio destinado para la colocación del EPP y otro espacio diferente para su retiro. ${ }^{31,32}$ Las secreciones, órganos y tejidos, sondas, catéteres y demás equipo invasivo en el paciente, al retirarse, se manejarán como residuos biológicos peligrosos infecciosos. ${ }^{33,34}$
- Siempre que se manipule el cadáver deben evitarse los movimientos bruscos, ya que generan aerosolización. ${ }^{26,28,30}$ El lugar donde se realiza la autopsia debe tener una adecuada circulación del aire que se aleje del trabajador de la salud y del cadáver en la plancha; por tanto, se recomienda el uso de filtros de partículas de alta eficiencia o salas con presión negativa. ${ }^{26}$ Debe evitarse a toda costa el uso de sierras eléctricas para la autopsia y para el manejo del tejido pulmonar e intestinal, ya que en estos casos existe una elevada carga viral. ${ }^{29}$

- Se recomienda que un número limitado del personal de salud maneje el cadáver. ${ }^{26,28,29}$

En cuanto a los familiares del difunto, las guías analizadas ${ }^{28,29,32,35}$ pueden llegar a un acuerdo con respecto a los siguientes conceptos:

- En caso de ocurrir una defunción en casa de un paciente diagnosticado con COVID-19, no es necesario realizar autopsias; se debe recomendar al familiar no entrar en contacto directo con el cuerpo y esperar a que el personal de salud, con el adecuado EPP, se haga cargo de la situación. ${ }^{28}$

- El personal médico debe de ser empático, ${ }^{28,36}$ recordando que, por la situación de la pandemia, la familia se encuentra pasando por un doble duelo: la pérdida de su familiar y de su estilo de vida habitual. . $9,36^{2}$

\section{Requisitos de embalaje de categoría B}
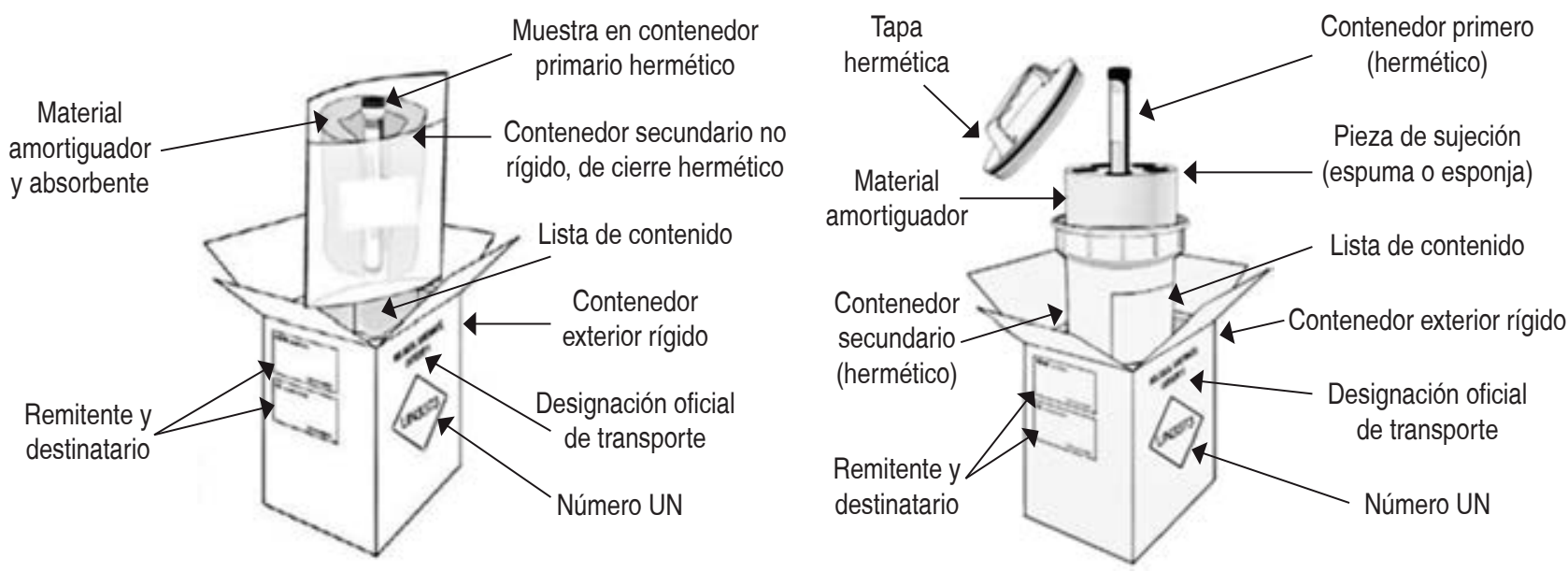

Figura 7: Embalaje de categoría B.

Tomado de: Protocolo de bioseguridad y biocustodia para el manejo de pacientes durante la toma de muestras de casos sospechosos por enfermedad por 2019NCoV. México. Secretaría de Salud Federal M. Protocolo de bioseguridad y biocustodia para el manejo de pacientes durante la toma de muestras de casos probables de enfermedad por 2019-nCoV [Internet]. 2019. Available from: http://cvoed.imss.gob.mx/wp-content/uploads/2020/02/Protocolo-de-Bioseguridad-y-Biocustodia2019-nCOV_InDRE_30_01_2020-1.pdf-1.pdf 


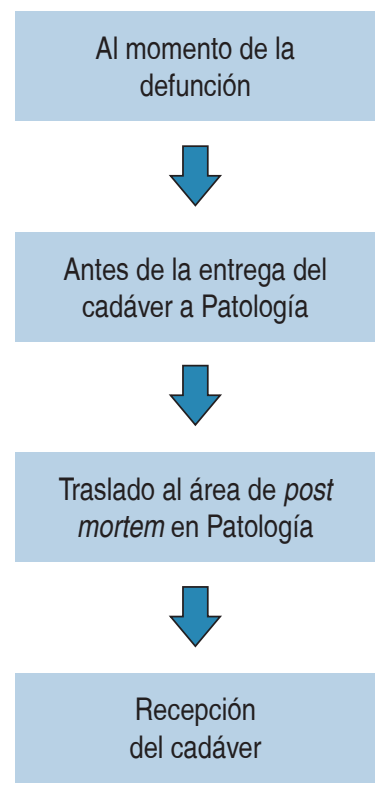

- El médico tratante debe:

- Verificar el diagnóstico de COVID-19 y consignarlo en el expediente

- Comunicar al Servicio de Patología el diagnóstico para iniciar las medidas necesarias

- Avisar a los familiares y personal administrativo para iniciar trámites correspondientes

- Uso de EPP y medidas de higiene adecuadas

- Retiro de todos los tubos, drenajes y catéteres y objetos punzocortantes relacionados

- Cobertura y desinfección de orificios con hipoclorito a 1\%. Posteriormente, amortajar con dos sábanas o con bolsa específica para cadáver. Identificar adecuadamente al cadáver con su nombre, fecha de nacimiento, expediente, fecha y hora de defunción y área del hospital

- Al envío, no se requiere un equipo de transporte especial, puede ir en una camilla, siguiendo la ruta de traslado designada

- Enviar la papelería correspondiente en una bolsa de plástico transparente

- Designar un área específica. Quien recibe el cadáver debe llevar a cabo higiene de manos y colocación de EPP antes de manipular el cadáver

- Adecuada identificación del paciente

- El cuerpo deberá de permanecer accesible las primeras 6 horas para permitir trámites funerarios y entrega; posteriormente debe de resguardarse en gavetas refrigeradas

Figura 8: Diagrama de pasos para el adecuado manejo de cadáveres con SARS-CoV-2.

Abreviaturas: COVID-19 = enfermedad por SARS-CoV-2; EPP = equipo de protección personal.

- Se puede permitir el acceso a los familiares y amigos, aunque quedará restringido sólo a los más próximos y cercanos, y siempre deberán usar EPP. Debe explicarse al familiar la necesidad de no tocar ni besar el cuerpo bajo los conceptos de mecanismos de transmisión de la enfermedad. ${ }^{29}$

- Debe orientarse a evitar un funeral (máximo de 20 personas) y limitar el tiempo de velación (máximo de 4 horas). ${ }^{28}$ Asimismo, no existe razón para discriminar grupos étnicos y creencias. Tampoco hay evidencia concluyente de que todos los cuerpos que cursaron con la enfermedad por SARSCoV-2 tengan que ser incinerados. ${ }^{26,29,32}$

En la Figura 8, se resume en un gráfico la serie de pasos necesarios para la manipulación del cadáver en el contexto de fallecimiento por enfermedad por COVID-19, según las disposiciones oficiales internacionales ${ }^{26,30}$ y nacionales. ${ }^{28,29}$

En el ámbito pediátrico, si bien se han reportado un limitado número de fallecimientos, ${ }^{36,37}$ las políticas de salud en procesamiento de cadáveres siguen los mismos lineamientos.

Como pediatras, nos tocará comunicar el fallecimiento de familiares cercanos a los niños, con quienes podemos aplicar los principios fundamentales de los cuidados paliativos: ${ }^{36}$ honestidad y confianza, siempre comunicar con la verdad y escuchar las preocupaciones del niño, e identificar cuáles actitudes pueden ser contraproducentes para el resto de la familia y cuáles pueden poner en riesgo. ${ }^{26,28,36}$

\section{COVID-19: PANDEMIA QUE NECESITA CRITERIOS ÉTICOS PARA LA ATENCIÓN}

La enfermedad por SARS-CoV-2 llegó a nuestro país de manera súbita, alterando la estabilidad emocional y de salud de toda la ciudadanía. La población no percibe la gravedad de la pandemia hasta no presentar los síntomas y llegar a un hospital. El INER, como en otros hospitales, se alteró ante la reconversión y atención del nuevo virus como su única función. El personal de salud mexicano carece de criterios éticos que puedan apoyarlo en su atención del paciente con coronavirus. por tal motivo, revisamos documentos legales, desde la Constitución Política de la República Mexicana hasta las guías de práctica y manuales operativos, además de que estudiamos la situación problemática del paciente contagiado y describimos algunas propuestas.

Ante esta emergencia sanitaria no se suspenderán las garantías individuales, respetando el artículo 4o. 
Rev Latin Infect Pediatr 2020; 33 (s1): s75-s95

de la Constitución Política de los Estados Unidos Mexicanos, que establece que toda persona tiene derecho a la protección de la salud, por lo que, en caso de epidemias de carácter grave o peligro de invasión de enfermedades exóticas en el país, la SS tendrá la obligación de dictar inmediatamente las medidas preventivas indispensables. ${ }^{38}$

Jorge Carlos Alcocer Varela, Secretario de Salud, con fundamento en la Constitución Política de los Estados Unidos Mexicanos, ${ }^{38}$ la Ley Orgánica de la Administración Pública Federal ${ }^{39}$ y la Ley General de Salud ${ }^{40}$ describe que el Estado Mexicano será el encargado de suministrar los recursos necesarios a los miembros vulnerables de la sociedad cuando las circunstancias los rebasen, garantizando el acceso a servicios de salud; el Estado está obligado a proveer al personal sanitario de insumos y medios físicos, médicos, quirúrgicos y técnicos indispensables para su salud e integridad física, con la finalidad de dar atención y seguridad a los pacientes. ${ }^{38}$

La Figura 9 muestra la visión de la situación problemática de la atención del COVID-19 por el profesional de la Salud del INER. ${ }^{41}$

\section{Criterios éticos}

La definición de «criterio» según la RAE es: «la norma para conocer la verdad; juicio o discernimiento ${ }^{42}$ y la definición de "ética» de la RAE es: "conjunto de normas morales que rigen la conducta de la persona en cualquier ámbito de la vida. Ética profesional, cívica, deportiva, etcétera».43 Los criterios éticos expuestos en este trabajo vinculan la relación entre el paciente y el profesional de la salud.

\section{Los criterios éticos de aplicación} de pruebas COVID-19

Así como lo señala el artículo 20. de la declaración de Emergencia Sanitaria, la cual se dictó por el Consejo de Salubridad General, ${ }^{44}$ es importante contar con los recursos materiales y humanos que nos permitan hacer frente a esta emergencia y tenerlos de manera eficiente. Asimismo, será importante que las decisiones éticas contemplen y valoren las posibilidades de sobrevivencia para quienes se asignen los recursos. Será de gran utilidad apoyarse en las escalas SOFA, qSOFA ${ }^{45,46}$ o APACHE II o III ${ }^{47}$ de manera integral sin jamás sustituir el criterio ni reflexión médica global.

Es de suma importancia, tener firmado el Consentimiento Informado por el paciente con COVID-19 o por el familiar, dependiendo de la gravedad, ${ }^{48,49}$ de manera oportuna, el cual especifica su diagnóstico, pronóstico y tratamiento; en caso de tratarse de pacientes vulnerables y con pocas probabilidades de sobrevivencia, plantearles el cuidado paliativo. ${ }^{50}$

\section{Criterio para la voluntad anticipada}

En caso de que el paciente no pueda expresar su voluntad anticipada, caerá en los «disponentes secundarios ${ }^{51} \mathrm{y}$, al no existir ningún familiar, el profesional de la salud tomará las decisiones basándose en la valoración integral y objetiva. La derivación de las deci-

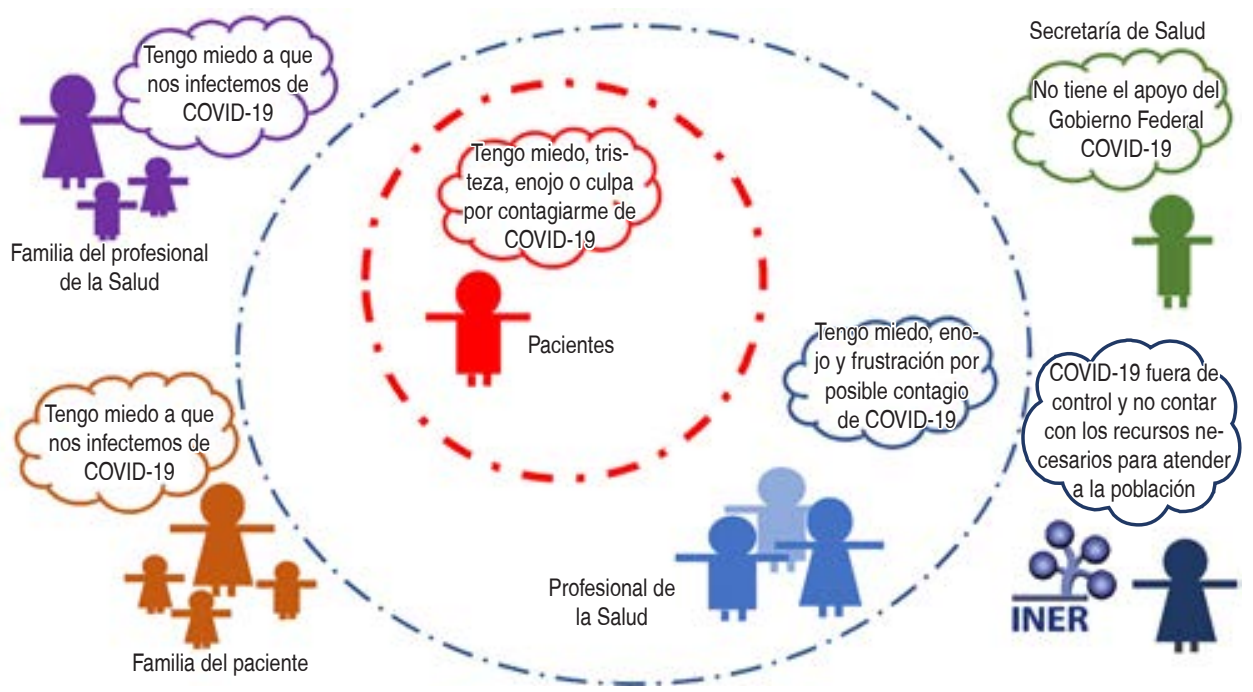

Figura 9:

Visión de la situación problemática de la atención del COVID-19 por el profesional de la Salud del INER.

Fuente: UNICEF (2020). Basado en: Checkland (1994). ${ }^{24,41}$ 
siones hacia los familiares se podrá hacer vía telefónica o mediante conexión con dispositivos móviles. ${ }^{52-54}$

No podrá extubarse por mal pronóstico o con la finalidad de proporcionárselo a otra persona, a ningún paciente sin su consentimiento o el de su familiar.

Sí la ventilación asistida está siendo fútil, se sugiere extubar; no sin antes verificarse nuevamente con las escalas SOFA ${ }^{45,46}$ o APACHE $^{47}$ y confirmar con otro colega el pronóstico, así como platicarlo con la familia sobre las decisiones médicas.

\section{Criterios para la objeción de conciencia del personal sanitario}

De acuerdo con la función que se desempeña, el profesional de la salud no podrá negar la atención a nadie, y menos basado en la falta de criterios, puesto que esto será sujeto a penalizaciones legales.

\section{Criterios para la atención y apoyo psicológico a los profesionales de la salud}

La salud mental es un componente esencial, integral y primordial en la vida de cualquier individuo. ${ }^{55}$ Sin embargo, la pandemia actual por COVID-19 está alterando la vida de toda la humanidad, en especial, la de los profesionales de la salud. Ellos deberán procurarse un momento de tranquilidad, así como momentos para su salud emocional y espiritual, ya que estos aspectos están aunados a su eficiencia en el desempeño de sus labores como humano. ${ }^{56}$

\section{Criterios de apoyo psicológico a pacientes y familiares}

Desde el momento del diagnóstico de una enfermedad, cuyo tratamiento requiere de un ingreso hospitalario, el paciente y el familiar pueden experimentar diversas alteraciones emocionales como ansiedad, estrés y depresión, entre otras. ${ }^{57}$

Para la familia del paciente, será importante sentirse apoyada en su desgaste físico y emocional; previamente, a la toma de decisión de la propuesta de extubación del paciente por mala evolución, se deberá tener una sesión de debriefing, la cual consiste en aliviar la carga del estrés asociada con la pérdida. ${ }^{55,56,58}$

\section{Criterios para el derecho del «último adiós»}

El «último adiós», hasta ahora, se permitía a los familiares como parte de un proceso de duelo en tanatología:59 sin embargo, dado que COVID-19 es altamente contagioso, se deberá buscar la manera en la cual el paciente y los familiares puedan despedirse por medio de contacto virtual, respetando las creencias, valores, y preferencias individuales. ${ }^{60,61}$

Criterios éticos para la disposición y manejo de los cadáveres confirmados con COVID-19

Se permitirá el acceso restringido a los familiares más próximos y cercanos a la persona fallecida para su reconocimiento, sin establecer contacto físico con el cadáver ni con las áreas del entorno que pudieran estar infectadas; en la medida de lo posible y ante la situación derivada de la pandemia del COVID-19, se puede recomendar la incineración del cadáver, respetando las creencias de los deudos. ${ }^{62}$

\section{Criterios éticos en los procesos de investigación durante la emergencia}

Con la finalidad de aprender del COVID-19 en su calidad de pandemia, se considera además el modelo de Aprendizaje Centrado en el Paciente ${ }^{63}$ para realizar los procesos necesarios que permita la investigación de la propagación, cura o elaboración de la vacuna.

Se ponderará el riesgo-beneficio si se trata con seres humanos, contando con un plan de contingencia que permita cubrir los posibles riesgos a la salud. Antes de iniciar con todos los proyectos de investigación, se tendrá que tener firmado el Consentimiento Informado del paciente o de los familiares; el estado de emergencia no autoriza a ningún investigador a omitir este proceso. ${ }^{48}$

Los resultados de estas investigaciones conducentes deben de ser del dominio público y existe el deber de compartirlas con todos los países que sufran de la misma emergencia sanitaria; en caso de encontrar curas o vacunas que sirvan para contrarrestar los efectos de las enfermedades causadas durante la emergencia sanitaria, la prioridad para su administración deberá ser hacia los profesionales de la salud en primer lugar y hacia las poblaciones vulnerables en segundo lugar. ${ }^{50}$

\section{Criterios éticos para el manejo de la información:}

a) Privacidad y confidencialidad de datos personales: de la revelación de la identidad. La identidad de las personas que han tenido diagnóstico positivo 
de COVID-19 deberá ser protegida y no deberá divulgarse en medios de comunicación masiva. Sin embargo, sus contactos más cercanos, como familiares y amigos con los que mantiene contacto cotidiano, podrán conocer el diagnóstico y recibir información pertinente sobre los riesgos y medidas preventivas de contagio; a su vez, familiares y amigos cercanos deberán mantener en reserva la identidad de personas contagiadas, evitando divulgar la información en medios de comunicación; esto se fundamenta en los principios de responsabilidad, respeto y prudencia. ${ }^{50,64}$

b) Relación de las personas con las que se tuvo contacto estando contagiado. Para atender el criterio relacionado con las personas que tuvieron contacto con algún paciente de COVID-19, se consultó y aplicó el documento «Prevención de la Transmisión de la Tuberculosis en las Unidades de Salud", de la Secretaría de Salud, ${ }^{42}$ el cual solicita al paciente la información relacionada con las personas con las que tuvo contacto. El profesional de la salud solicitará: a) nombre, b) domicilio para su ubicación y c) teléfono y/o celular, con la finalidad de dar seguimiento a potenciales personas infectadas y proceder con los protocolos correspondientes de observación, diagnóstico y, en su caso, cuarentena. ${ }^{42}$

En conclusión, esta propuesta pretende que el personal de salud del INER y otros hospitales, cuente con los criterios éticos para la toma de decisiones frente a un panorama catastrófico en la salud que vive nuestro país, sin que esto le cause una carga emocional adicional negativa.

Dada la problemática legal actual, el personal de salud debe evaluar y aplicar todas las estrategias ante esta emergencia sanitaria, ya que los protocolos variarán constantemente; procurando recuperar la salud del paciente, sin que esto implique malas interpretaciones por parte de la sociedad, los familiares, e inclusive, por el propio paciente, con la finalidad de evitar un proceso jurídico posterior.

También las instituciones de salud deben tomar las previsiones necesarias para la defensa legal de su personal. Evidentemente, esta pandemia generará un duelo diferente, ya que se verá alterado el proceso y las fases; al duelo además se le sumarán emociones provocadas por el confinamiento, de no poder compartir contacto ni cercanía con sus seres amados y el no poder llevar de forma natural las pérdidas. El duelo es un proceso personal e íntimo, que lo experimentamos de diversas formas; no pode- mos compararnos: no hay un modelo normal, cada persona tendrá una forma de vivir y superar ese duelo.

\section{REFERENCIAS}

1. Centro de Coordinación de Alertas y Emergencias Sanitarias. Dirección General de Salud Pública, Calidad e Innovación. Manejo pediátrico en atención primaria del COVID-19 [Internet]. Versión del 18 de junio de 2020. Disponible en: https://www.mscbs.gob.es/profesionales/ saludPublica/ccayes/alertasActual/nCov-China/ documentos/Manejo_pediatria_ap.pdf

2. Organización Mundial de la Salud (OMS). Manejo clínico de la infección respiratoria aguda grave presuntamente causada por el nuevo coronavirus (2019-nCoV) Orientaciones provisionales [Internet]. 2020 (orientaciones provisionales). Disponible en: https://apps.who.int/iris/ bitstream/handle/10665/330938/WHO-nCoV-Clinical2020.3-spa.pdf

3. European Centre for Disease Prevention and Control. Novel coronavirus (SARS-CoV-2) discharge criteria for confirmed COVID-19 cases - When is it safe to discharge COVID-19 cases from the hospital or end home isolation? [Internet]. ECDC Technical Report. 2020. pp. 1-5. Available from: https://www.ecdc.europa.eu/sites/default/files/documents/ COVID-19-Discharge-criteria.pdf

4. Rothe C, Schunk M, Sothmann P, Bretzel G, Froeschl G, Wallrauch $C$ et al. Transmission of 2019-NCOV infection from an asymptomatic contact in Germany. N Engl J Med. 2020; 382 (10): 970-971.

5. Cheung KS, Hung IF, Chan PP, Lung KC, Tso E, Liu R et al. Gastrointestinal manifestations of SARS-CoV-2 infection and virus load in fecal samples from the Hong Kong Cohort and systematic review and meta-analysis. Gastroenterology [Internet]. 2020. Available from: https://doi.org/10.1053/j. gastro.2020.03.065

6. Sociedad Española de Enfermedades Infecciosas y Microbiología Clínica. Consideraciones SEIMC para dar de alta a personal sanitario con COVID-19 [Internet]. 2020. Disponible en: https://seimc.org/contenidos/ documentoscientificos/recomendaciones/seimc-rc-2020alta personal sanitario con_covid-19.pdf

7. Jiehao C, Jin X, Daojiong L, Zhi Y, Lei X, Zhenghai $Q$ et al. A case series of children with 2019 novel coronavirus infection: clinical and epidemiological features. Clin Infect Dis [Internet]. 2020; 71 (6): 1547-1551. Available from: https://watermark.silverchair.com/ciaa198.pdf?token=AQ ECAHi208BE49Ooan9kkhW_Ercy7Dm3ZL_9Cf3qfKAc48 5ysgAAAmswggJnBgkqhkiG9w0BBwagggJYMIICVAIBAD CCAk0GCSqGSIb3DQEHATAeBglghkgBZQMEAS4wEQ QM1i3M7PHkC6dAzL12AgEQgllCHtn40-AX0dBKm8bw1kHsLT7OPT9cbRqoEDGRGxEbQOEYp1

8. CDC. Interim Clinical Guidance for Management of Patients with Confirmed Coronavirus Disease (COVID-19) [Internet]. 2020. Available from: https://www.cdc.gov/ coronavirus/2019-ncov/hcp/clinical-guidance-managementpatients.html

9. Sociedad Española de Neonatología. Recomendaciones para el manejo del recién nacido en relación con la infección por SARS-CoV-2. Versión 5.0. 23/03/2020 [Internet]. 2020. Disponible en: https://www.analesdepediatria.org/contenidos/ pdf/Recomendaciones_pediatricas_Covid2.pdf?1 
10. Organización Mundial de la Salud. Atención en el domicilio a pacientes presuntamente infectados por el nuevo coronavirus (COVID-19) que presentan síntomas leves, y gestión de sus contactos. [Internet]. 2020. Disponible en: https://apps.who.int/iris/bitstream/ handle/10665/331397/WHO-nCov-IPC-HomeCare-2020.2spa.pdf?sequence $=1$ \&is Allowed $=y$

11. Secretaría de Salud Federal. Proceso de prevención de infecciones para las personas con COVID-19 (enfermedad por SARS-CoV-2). Contactos y personal de salud [Internet]. Disponible en: http://cvoed.imss.gob.mx/wp-content/ uploads/2020/02/Prevención_COVID-19.pdf.pdf

12. Sociedad Argentina de Pediatría. Segundo documento COVID-19. Recomendaciones para la Atención del Paciente Pediátrico con Infección SARS-CoV-19 [Internet]. 2009. p. 1-3. Disponible en: https://www.sap.org.ar/uploads/archivos/ general/files_segundo-encuentro-virtual-covid_1585328932.pdf

13. ESPNIC. Nursing guidance for the care of the child with suspected or proven COVID-19 infection Nursing guidance for the care of the child with suspected or proven COVID-19 Infection [Internet]. 2020. Available from: https://espniconline.org/News/Latest-News/Nursing-guidance-for-thecare-of-the-child-with-suspected-or-proven-COVID-19infection2

14. Verbeek JH, Rajamaki B, ljaz S, Tikka C, Ruotsalainen $\mathrm{JH}$, Edmond $\mathrm{MB}$ et al. Personal protective equipment for preventing highly infectious diseases due to exposure to contaminated body fluids in healthcare staff. Cochrane Database Syst Rev. 2019; 7: CD011621.

15. FDA. Questions about personal protective equipment (PPE) [Internet]. 2020. Available from: https://www.fda.gov/ medical-devices/personal-protective-equipment-infectioncontrol/questions-about-personal-protective-equipment-ppe

16. CDC: Guidance for the selection and use of PPE in healthcare settings [Internet]. 2020. p. 1-49. Available from: https://www.joinbuiltforzero.org/covid19-resources/cdcguidance-for-the-selection-and-use-of-ppe-in-healthcaresettings/

17. World Health Organization (WHO). Infection prevention and control of epidemic- and pandemicprone acute respiratory infections in health care. 2014. pp. 1-156. Available from: http://apps.who.int/iris/ bitstream/10665/112656/1/9789241507134 eng.pdf?ua=1

18. Secretaría de Salud. Norma Oficial Mexicana NOM-087ECOL-SSA1-2002, Protección ambiental. Salud ambiental. Residuos peligrosos biológico-infecciosos. Clasificación y especificaciones de manejo [Internet]. Diario Oficial de la Federación. Disponible en: http://www.salud.gob.mx/ unidades/cdi/nom/087ecolssa.html

19. Báez MM. Sospechosos por enfermedad por 2019-NCoV. Instituto de Diagnóstico y Referencia Epidemiológicos [Internet]. 2020. Disponible en: https://www.gob.mx/ $\mathrm{cms} /$ uploads/attachment/file/531376/Protocolo_de Bioseguridad_y_Biocustodia_2019-nCOV_Caso_ sospechosos InDRE 31012020.pdf

20. Departamento de Trabajo de EUA. Administración de Seguridad y Salud Ocupacional. Guía sobre la Preparación de los Lugares de Trabajo para el virus COVID-19 [Internet]. 2020. Disponible en: https://www.osha.gov/Publications/ OSHA3992.pdf

21. PCB Guidelines for handling, treatment and disposal of waste generated during treatment/diagnosis/quarantine of COVID-19 patients [Internet]. Parivesh Bhawan, East
Arjun Nagar: Central Pollution Control Board, Delhi; 2020. Available from: https://www.tnpcb.gov.in/pdf_2020/ Guideline_COVID_19_waste.pdf

22. World Health Organization (WHO). Water, sanitation, hygiene and waste management for the COVID-19 virus [Internet]. World Health Organization. 2020. Available from: https://www.who.int/publications-detail/water-sanitationhygiene-and-waste-management-for-covid-19

23. World Health Organization (WHO). Guía sobre la reglamentación relativa al transporte de sustancias infecciosas 2009-2010 [Internet]. 2010. Disponible en: https://www.who.int/csr/resources/publications/biosafety/ WHO HSE EPR_2008_10_ES.pdf

24. Calvo Rey M, García-López Hortelano J, Tomás Ramos F, Baquero Navarro M. Documento de manejo clínico del paciente pediátrico con infección por SARS-CoV-2. Extracto del Documento de Manejo Clínico del Ministerio de Sanidad Redactores pertenecientes a la Asociación Española de Pediatría (AEP): Sociedad Española de Infectología Pediátrica [Internet]. 2020. pp. 1-17. Disponible en: https://www.analesdepediatria.org/contenidos/pdf/ Recomendaciones_pediatricas_Covid1.pdf

25. Organización Panamericana de la Salud. Directrices de laboratorio para la detección y diagnóstico de la Infección con el Nuevo Coronavirus 2019 (2019-nCoV) [Internet]. Vol. 1. PAHO-WHO. 2020. p. 5. Disponible en: https:// iris.paho.org/bitstream/handle/10665.2/51894/ncov-labrecomendaciones-es.pdf? sequence $=1$ \&isAllowed $=y$

26. CDC. Collection and submission of postmortem specimens from deceased persons with known or suspected COVID-19 (Interim Guidance) [Internet]. 2020. Available from: https:// www.cdc.gov/coronavirus/2019-ncov/hcp/guidancepostmortem-specimens.html

27. Korean Society of Infectious Diseases and Korea Centers for Disease Control and Prevention. Analysis on 54 mortality cases of coronavirus disease 2019 in the republic of Korea from January 19 to March 10, 2020. J Korean Med Sci. 2020; 35 (12): e132.

28. Instituto Nacional de Enfermedades Respiratorias. Protocolo para el manejo de cadáveres COVID-19. México: Secretaría de Salud; 2020.

29. Secretaría de Salud. Guía de manejo de cadáveres por COVID-19 SARS-CoV-2 en México. [Internet]. 2020. p. 1-12. Disponible en: https://coronavirus.gob.mx/wpcontent/uploads/2020/04/Guia_Manejo_Cadaveres_ COVID-19.pdf

30. Organización Panamericana de la Salud. Manejo de cadáveres en el contexto del nuevo coronavirus (COVID-19). OPS/OMS [Internet]. 2020; 1-5. Disponible en: https://iris.paho.org/bitstream/ handle/10665.2/52000/OPSPHEIHMCovid1920002_spa. pdf? sequence $=1$ \&isAllowed $=y$

31. Carnicero S, Hermida T. Procedimiento para el manejo de cadáveres de casos de COVID-19. Asociación Española de Anatomía Patológica (SEAP). Ministerio de Sanidad [Internet]. 2020. pp. 1-10. Disponible en: https://www.mscbs. gob.es/profesionales/saludPublica/ccayes/alertasActual/ nCov-China/documentos/Manejo_cadaveres_COVID-19.pdf

32. Rodríguez E, Mejía-Santos HM. Lineamientos para el manejo de cadáver por casos de COVID-19. Secretaría de Salud República Honduras [Internet]. 2020. Disponible en: http://www.desastres.hn/COVID-19/Lineamientos. de.Manejo.de.Cadaver.de.casos.por.Covid-19.pdf 
Rev Latin Infect Pediatr 2020; 33 (s1): s75-s95

33. Hanley B, Lucas SB, Youd E, Swift B, Osborn M. Autopsy in suspected COVID-19 cases. J Clin Pathol. 2020; 73 (5): 239-242.

34. Osborn M, Lucas S, Stewart R, Swift B, Youd E. Briefing on COVID-19: autopsy practice relating to possible cases of COVID-19 (2019-nCov, novel coronavirus from China 2019/2020). London: The Royal College of Patholog College of Pathologists; 2020.

35. Ministerio de Salud y Protección Social. Orientaciones para el manejo, traslado y disposición final de cadáveres por COVID-19. [Internet]. Ministerio de Salud y Protección Social de Colombia. 2020. Disponible en: https:// www.minsalud.gov.co/Paginas/Orientaciones-para-ladisposicion-de-cadaveres-frente-a-la-pandemia-de-lacovid-19.aspx

36. Weaver MS, Wiener L. Applying palliative care principles to communicate with children about COVID-19. J Pain Symptom Manage [Internet]. 2020; 60 (1): e8-e11. Available from: https://www.jpsmjournal.com/action/showPdf?pii $=$ S0885-3924\%2820\%2930171-8

37. Ruan S. Likelihood of survival of coronavirus disease 2019. Lancet Infect Dis [Internet]. 2020; 20 (6): 630-631. Available from: https://www.thelancet.com/pdfs/journals/laninf/ PIIS1473-3099(20)30257-7.pdf

38. Gobierno Federal de la República Mexicana. Constitución Política de los Estados Unidos Mexicanos. DOF 29-012016. 1917; 1-287.

39. Gobierno Federal de la República Mexicana. Ley Orgánica de la Administración Pública Federal. Gobierno de la República. 2014. p. 152.

40. Gobierno Federal de la República Mexicana. Ley General de Salud. México: México; 2016. p. 44.

41. Checkland P. La metodología de sistemas suaves en acción. México D.F.: LIMUSA y Grupo Noriega Editores; 1994. p. 353

42. Secretaría de Salud. Prevención de la transmisión de la tuberculosis en las unidades de salud. Programa Nacional de Tuberculosis; 1992. p. 16.

43. Diccionario de la Lengua Española. Ético [Internet]. 34..$^{a}$ ed. Real Academia Española. Madrid: RAE; 2005, p. 1 y 6.

44. Asociación Mexicana de Pediatría. COVID-19 en pediatría [Internet]. 2020. pp. 1-10. Disponible en: https://amp.org.mx/ portfolio/covid-19-en-pediatria/

45. El-Mashad GM, El-Mekkawy MS, Zayan MH. La escala pediátrica de evaluación del fallo multiorgánico secuencial (pSOFA): una nueva escala de predicción de la mortalidad en la unidad de cuidados intensivos pediátricos. An Pediatr (Barc). 2020; 92 (5): 277-285.

46. Anáhuac México. Guía de criterios éticos ante emergencias sanitarias en México en el contexto de la pandemia por COVID-19 [Internet]. Ciudad de México; 2020. Disponible en: https://www.anahuac.mx/mexico/EscuelasyFacultades/ bioetica/sites/default/files/inline-files/Guia_de_criterios eticos_COVID19.pdf

47. Lin HC, Chiang LC, Wen TN, Yeh KW, Huang JL. Development of online diary and self-management system on e-Healthcare for asthmatic children in Taiwan. Comput Methods Programs Biomed. 2014; 116 (3): 299-310.

48. UNESCO. Aspectos éticos de la investigación en seres humanos [Internet]. Susana Vidal. Red Latinoamericana y del Caribe de Bioética. 2016. pp. 1-20. Disponible en: http:// redceih.bvs.hn/wp-content/uploads/2016/12/Aspectos_ eticos de la investigacion en seres humanos.pdf

49. INER. Deberes y derechos del paciente y su familia. Man Organ del INER. 2017; 25.

50. Organización Mundial de la Salud (OMS). Contribución de la ética a la salud pública [Internet]. 2020. p. 5. Disponible en: https://www.who.int/bulletin/volumes/86/8/08-055954/es/

51. Gobierno Federal de la República Mexicana. Reglamento de la Ley General de Salud en materia de control sanitario de la disposición de órganos, tejidos y cadáveres de seres. Gobierno de la República; 1983. p. 23.

52. INAPAM. Ley de voluntad anticipada: el derecho a una muerte digna [Internet]. 2019. Disponible en: https://www. gob.mx/inapam/articulos/ley-de-voluntad-anticipada-elderecho-a-una-muerte-digna

53. Gobierno del Distrito Federal. Ley de Voluntad Anticipada, legislación penal y Ley de salud de la Ciudad de México. Vol. 14, CONAMED-OPS. Del Centro de Colaborador de Calidad y Seguridad en el Paciente. 2016. p. 4.

54. Gobierno de la Ciudad de México. Acciones. Voluntad Anticipada [Internet]. 2020. p. 12. Disponible en: https:// www.salud.cdmx.gob.mx/actividades/voluntad-anticipada

55. Santacruz-Escudero J. Una revisión acerca del debriefing como intervención en crisis y para la prevención del TEPT (trastorno d estrés postraumático). Rev Colomb Psiquiatr. 2008; 37 (1): 198-205.

56. Universidad Rafael Landívar. Experiencia de debriefing en ambos grupos de acompañamiento de psicólogos voluntarios de la Universidad Rafael Landivar en la intervención postdesastre en San Marcos [Tesis]. Guatemala: Universidad Rafael Landívar; 2014.

57. Organización Mundial de la Salud (OMS). Salud mental en las emergencias [Internet]. OMS. 2019. p. 6. Disponible en: https://www.who.int/es/news-room/fact-sheets/detail/ mental-health-in-emergencies

58. Lebrón Carbonell I. Debriefing Group. Intervenciones ante sucesos traumáticos. España: Universitat de les Illes Balears; 2015.

59. Piélago-García L. Muerte y conspiración del silencio. Vol. 53. Asociación de Educación Continua y a Distancia, A.C. 1989.

60. The New York Times. En el frente de combate de una pandemia , un "te amo" puede significar "adiós". The New York Times; 2020. p. 6.

61. Contreras A. Pacientes terminales dan el último adiós por videollamada ante coronavirus en Italia. El Universal; 2020. p. 1-7.

62. INER. Protocolo para el manejo de cadáveres COVID-19. Secretaría de Salud. 2020. p. 9.

63. Olivares-Olivares S, Valdéz J. Aprendizaje centrado en el paciente. Ciudad de México: Editorial Medica Panamericana; 2017. p. 302.

64. Gobierno Federal de la República Mexicana. Ley General de Protección de Datos Personales en Posesión de Sujetos Obligados. Diario Oficial de la Federación. 2017. pp. 1-52.

\footnotetext{
Correspondencia:

Dra. Laura Elena Carreto Binaghi

E-mail: lecarreto@iner.gob.mx
} 